\title{
Clarifications on the "Comparison Between SMOS, VUA, ASCAT, and ECMWF Soil Moisture Products Over Four Watersheds in U.S."
}

\author{
Wolfgang Wagner, Senior Member, IEEE, Luca Brocca, Vahid Naeimi, Rolf Reichle, \\ Clara Draper, Richard de Jeu, Dongryeol Ryu, Chun-Hsu Su, Andrew Western, \\ Jean-Christophe Calvet, Yann H. Kerr, Fellow, IEEE, Delphine J. Leroux, Matthias Drusch, \\ Thomas J. Jackson, Fellow, IEEE, Sebastian Hahn, Wouter Dorigo, and Christoph Paulik
}

\begin{abstract}
In a recent paper, Leroux et al. compared three satellite soil moisture data sets (SMOS, AMSR-E, and ASCAT) and ECMWF forecast soil moisture data to in situ measurements over four watersheds located in the United States. Their conclusions stated that SMOS soil moisture retrievals represent "an improvement [in RMSE] by a factor of 2-3 compared with the other products" and that the ASCAT soil moisture data are "very noisy and unstable." In this clarification, the analysis of Leroux et al. is repeated using a newer version of the ASCAT data and additional metrics are provided. It is shown that the ASCAT retrievals are skillful, although they show some unexpected behavior during summer for two of the watersheds. It is also noted that the improvement of SMOS by a factor of 2-3 mentioned by Leroux $e t$ al. is driven by differences in bias and only applies relative to AMSR-E and the ECWMF data in the now obsolete version investigated by Leroux $e t$ al.
\end{abstract}

Manuscript received August 13, 2013; accepted September 11, 2013. Date of publication October 22, 2013; date of current version December 17, 2013. This work was supported in part by EUMETSAT through the H-SAF project (hsaf.meteoam.it) and in part by the European Space Agency through the International Soil Moisture Network project.

W. Wagner, V. Naeimi, S. Hahn, W. Dorigo, and C. Paulik are with the Department of Geodesy and Geoinformation, Vienna University of Technology (TU Wien), 1040 Vienna, Austria (e-mail: wolfgang.wagner@geo.tuwien. ac.at).

L. Brocca is with the Research Institute for Geo-Hydrological Protection, National Research Council, 06128 Perugia, Italy (e-mail: luca.brocca@ irpi.cnr.it).

R. Reichle and C. Draper are with the Global Modeling and Assimilation Office, NASA Goddard Space Flight Center, Greenbelt, MD 20771 USA (e-mail: rolf.reichle@nasa.gov; clara.draper@nasa.gov).

R. de Jeu is with the Department of Earth Sciences, Free University of Amsterdam, 1081HV Amsterdam, The Netherlands (e-mail: r.a.m.de.jeu@vu.nl).

D. Ryu, C.-H. Su, and A. Western are with the Department of Infrastructure Engineering, University of Melbourne, Melbourne, Vic. 3010, Australia (e-mail: dryu@unimelb.edu.au; csu@unimelb.edu.au; a.western@unimelb. edu.au).

J.-C. Calvet is with Centre National de Recherches Météorologiques, Météo France, 31057 Toulouse, France (e-mail: jean-christophe.calvet@meteo.fr).

Y. H. Kerr and D. J. Leroux are with the Centre d'Etudes Spatiales de la Biosphere, 31401 Toulouse, France (e-mail: yann.kerr@cesbio.cnes.fr; delphine. leroux@cesbio.cnes.fr).

M. Drusch is with the European Space Research and Technology Centre, European Space Agency, 2201AZ Noordwijk, The Netherlands (e-mail: matthias.drusch@esa.int).

T. J. Jackson is with the Agricultural Research Service, Hydrology and Remote Sensing Laboratory, U.S. Department of Agriculture, Beltsville, MD 20705 USA (e-mail: tom.jackson@ars.usda.gov).

Color versions of one or more of the figures in this paper are available online at http://ieeexplore.ieee.org.

Digital Object Identifier 10.1109/TGRS.2013.2282172
Index Terms-Advanced Scatterometer (ASCAT), noise characterization, soil moisture, Soil Moisture and Ocean Salinity (SMOS), validation.

\section{INTRODUCTION}

$\mathbf{I}$ $\mathrm{N}$ a recent study, Leroux et al. [1] validated four global soil moisture data sets: 1) retrievals derived from L-band brightness temperature observations acquired by the Soil Moisture and Ocean Salinity (SMOS) mission [2]; 2) retrievals derived from the X-band brightness temperature data of the Advanced Microwave Scanning Radiometer-Earth Observing System (AMSR-E) [3]; 3) retrievals derived from C-band backscatter data acquired by the Advanced Scatterometer (ASCAT) [4]; and 4) model-based estimates produced by the European Centre for Medium Range Weather Forecasts (ECMWF) [5].

The validation was carried out over four intensive groundbased observing networks operated by the Agricultural Research Service (ARS) of the United States Department of Agriculture (USDA): Walnut Gulch (WG) in Arizona, Little Washita (LW) in Oklahoma, Little River (LR) in Georgia, and Reynolds Creeks (RC) in Idaho [6]. For each of these watersheds, arearepresentative soil moisture values were derived by averaging the measurements of several in situ sensors located at a depth of about $5 \mathrm{~cm}$. Based on these watershed averages, Leroux et al. calculated the linear correlation coefficient $R$, the standard error of estimate (SEE), the bias, and the root mean square error (RMSE), where RMSE ${ }^{2}=\mathrm{SEE}^{2}+$ bias $^{2}$.

Given that the comparison of remotely sensed and modeled soil moisture data with in situ measurements is an important component of the overall validation effort, we regard the work of Leroux et al. as a valuable contribution to the ongoing validation efforts for global soil moisture data sets. However, we feel that the statements regarding the skill of SMOS and ASCAT given in the conclusions and abstract of Leroux et al. can be misinterpreted and require some clarifications. The analysis of Leroux et al. is repeated here for the same study sites and time period but using a newer version of the ASCAT data and after converting the ASCAT data to volumetric soil moisture units $\left(\mathrm{m}^{3} \mathrm{~m}^{-3}\right)$ based on porosity values from a global data set, thereby providing additional skill metrics for ASCAT that were not given in [1]. Section II presents a brief discussion of the data sets and methods used here, Section III discusses the results of our analysis, and Section IV offers conclusions. 


\section{Data Sets And Methods}

\section{A. Data Set Versions}

Like Leroux et al., we use the version of the SMOS soil moisture data set available at that time from the operational center (version 5.01) (The current operational version is 5.51). To avoid a negative impact of radio frequency interference (RFI) on the SMOS measurements, we screened the data with the "RFI probability" flag (must be lower than 0.10) and the "SM DQX" flag (must indicate a successful retrieval, i.e., must not be -999; according to [7], a good value for filtering is DQX $<0.07)$. For ASCAT, Leroux et al. used data processed with the initial near-real-time processor implemented by EUMETSAT [8]. Here, we use the ASCAT data set reprocessed with the latest version of the software developed by TU Wien (Water Retrieval Package, version 5.5) which benefits from updates in the instrument calibration, model parameters, and algorithms [9], [10].

\section{B. Spatial Interpolation}

Leroux et al. reprojected the ASCAT, AMSR-E, and ECMWF soil moisture data in their respective original spatial resolutions onto the SMOS grid. Here, the SMOS and ASCAT retrievals were interpolated to points located in the center of the four USDA-ARS watersheds: WG $\left(31.72^{\circ} \mathrm{N}, 110.02^{\circ} \mathrm{W}\right)$, LW $\left(34.95^{\circ} \mathrm{N}, 98.10^{\circ} \mathrm{W}\right), \mathrm{LR}\left(31.65^{\circ} \mathrm{N}, 83.61^{\circ} \mathrm{W}\right)$, and RC $\left(43.15^{\circ} \mathrm{N}, 116.78^{\circ} \mathrm{W}\right)$. The interpolation was done using a Hamming window with a radius of $41 \mathrm{~km}$ to ensure that both satellite data sets have similar spatial resolutions.

\section{Units}

While SMOS, AMSR-E, and ECMWF data are expressed in terms of the volumetric soil moisture content (given in $\mathrm{m}^{3} \mathrm{~m}^{-3}$ ), ASCAT surface soil moisture data are presented as a degree of saturation (as a fraction or in percent). In order to visually compare the ASCAT data with the in situ measurements (given in $\mathrm{m}^{3} \mathrm{~m}^{-3}$ ), Leroux et al. rescaled the ASCAT data between the minimum and maximum values of the in situ data. Nonetheless, in their Table II, they only reported $R$ values (and not SEE, bias, or RMSE-values) because "by performing this rescaling, the ASCAT statistical results are improved unfairly in comparison with the other data sets because the bias is removed."

An alternative objective approach is to rescale the ASCAT surface soil moisture data $m_{s}$ into a volumetric soil moisture content $\theta$ using the ancillary soil porosity $\phi$ (given in $\mathrm{m}^{3} \mathrm{~m}^{-3}$ ) [4], [11], [12]

$$
\theta=m_{s} \cdot \phi
$$

where soil porosity data may, e.g., be estimated from available global soil maps. This approach is used here to calculate SEE, bias, and RMSE also for ASCAT. We estimated the porosity values by applying the equations of Saxton and Rawls [13] to the texture characteristics of the Harmonized World Soil Database [14]. The resulting porosity values are as follows: $0.406 \mathrm{~m}^{3} \mathrm{~m}^{-3}$ for WG, $0.456 \mathrm{~m}^{3} \mathrm{~m}^{-3}$ for $\mathrm{LW}, 0.438 \mathrm{~m}^{3} \mathrm{~m}^{-3}$ for $\mathrm{LR}$, and $0.456 \mathrm{~m}^{3} \mathrm{~m}^{-3}$ for RC.

\section{Masking}

All soil moisture data are masked for the occurrence of frost (minimum daily temperature recorded at the nearest meteorological station $\leq 0^{\circ} \mathrm{C}$ ) and snow (ERA-Interim snow water equivalent $>0$ ). Precipitation (rainfall and snowfall) was derived from the three hourly data generated by the Global Land Data Assimilation System (GLDAS) [15].

\section{E. Small Sample Size}

As listed in their Table II, the sample sizes used by Leroux et al. for calculating the error metrics ranged between 35 and 74 data pairs because data from only ten months (January 1 to November 9, 2010) were used, with morning and evening observations evaluated separately. Furthermore, they required data from all five sources to be available on each date to ensure a fair comparison. However, given the limited time period of their study, a drawback of this approach is that the resulting sample sizes were low, resulting in large statistical uncertainties.

Therefore, unlike Leroux et al. we computed the statistics using all available SMOS and ASCAT measurements (after masking for frost and snow) and without differentiating morning from evening data. For this reason, instead of using only 50-70 measurements, we used at least 250 SMOS/ASCAT measurements to calculate the metrics at each site. For ASCAT, we also calculated the statistics after masking problematic time periods for the WG and LR sites (see next section). Additionally, we repeated all computations using only morning/evening passes with both SMOS and ASCAT data, as was done by Leroux et al. (not shown). This reduced the sample size by $35 \%-55 \%$ depending on the site and sensor, but the general conclusions drawn for the different sites and the two sensors did not change.

\section{RESUlTS AND Discussion}

\section{A. Analysis of Time Series}

Figs. 1-4 show the volumetric soil moisture data estimated from ASCAT, SMOS, and the in situ measurements for the four USDA-ARS watersheds. The figures indicate that both SMOS and ASCAT exhibit a higher temporal variability than the in situ data. This is partly due to the higher noise of the satellite retrievals compared with the noise of the in situ data, but it also has physical reasons: While the satellite estimates represent the soil moisture content in the top few centimeters of the soil, the in situ data represent the soil moisture content in the subsurface soil layer centered at the installation depth of the sensors $(5 \mathrm{~cm})$. Therefore, the satellite data are more sensitive to atmospheric forcings (precipitation, radiation, and evaporative demand) which, in addition to the noise, explains their higher temporal variability and higher dynamic range.

First, we consider whether ASCAT exhibits a more dynamic and/or noisier behavior than SMOS. This could be expected given that the penetration depth of the C-band ASCAT data is shallower than that of the L-band SMOS data. However, in our view, Figs. 1-4, do not show the ASCAT data to be obviously noisier, and so, we performed a spectral analysis (not shown) to 


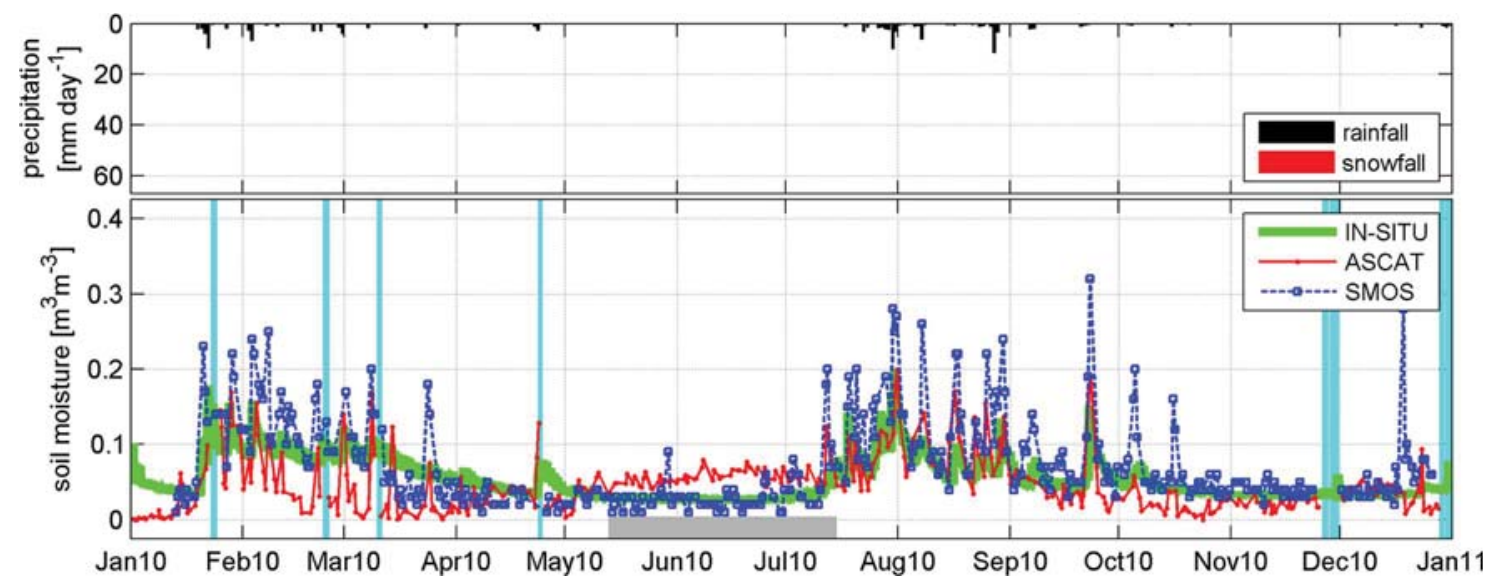

Fig. 1. Comparison of (blue dotted line) SMOS and (red line) ASCAT volumetric soil moisture $\left(\mathrm{m}^{3} \mathrm{~m}^{-3}\right.$ ) with (green thick line) in situ measurements over the WG observation network for the year 2010. The top panel shows GLDAS precipitation (in millimeters). The time periods when the satellite data were potentially affected by frost and/or snow cover are indicated by the shaded light-blue lines. The problematic summer period, as discussed in the text, is indicated by the gray horizontal bar.

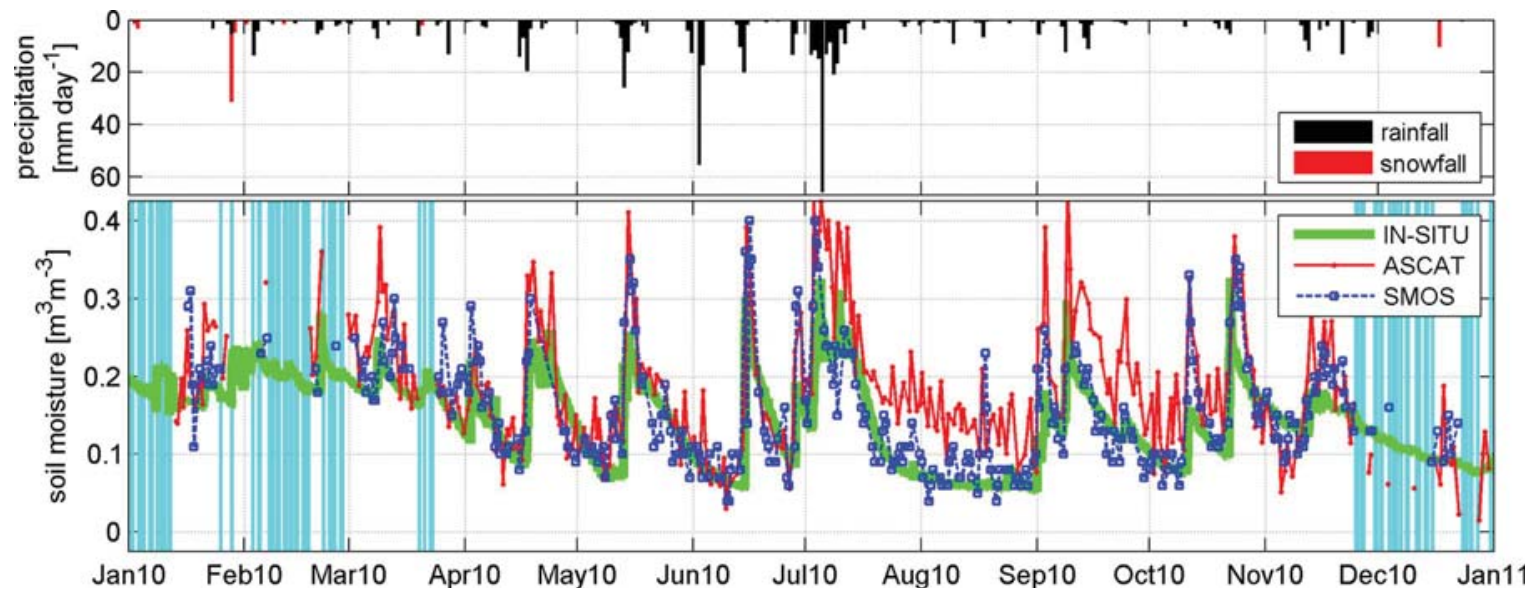

Fig. 2. Same as for Fig. 1 but for LW.

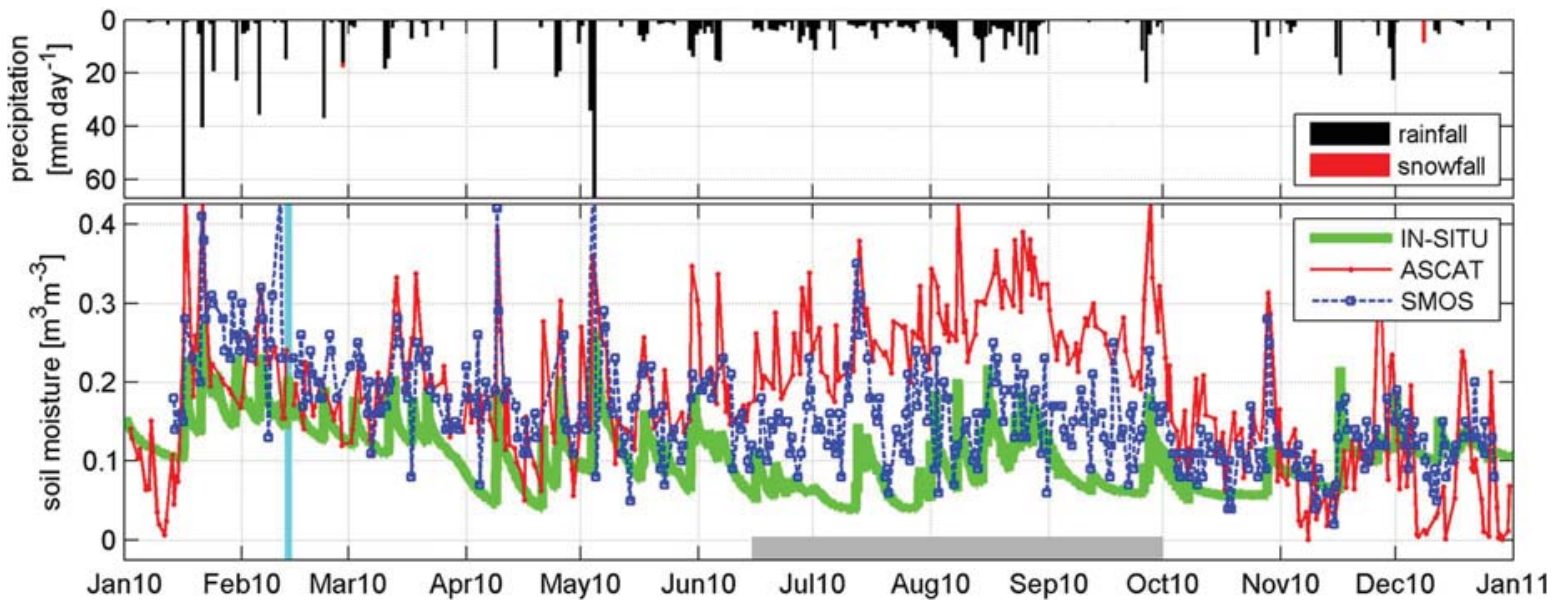

Fig. 3. Same as for Fig. 1 but for LR.

determine the stochastic component of the SMOS and ASCAT data [16]. This analysis showed that the stochastic component of ASCAT is slightly larger than for SMOS over LW and RC and slightly lower over WG, while for LR, the results are similar for both satellites. In other words, our analysis did not reveal any evidence that ASCAT is noisier than SMOS. The higher noise of ASCAT noted by Leroux et al. may be due to the fact that they linearly interpolated the $25-\mathrm{km}$ ASCAT data to the SMOS grid, while here, the ASCAT data were aggregated to roughly the SMOS spatial resolution using a Hamming window approach (Section II). Recall also that a newer version of the ASCAT data was used here. 


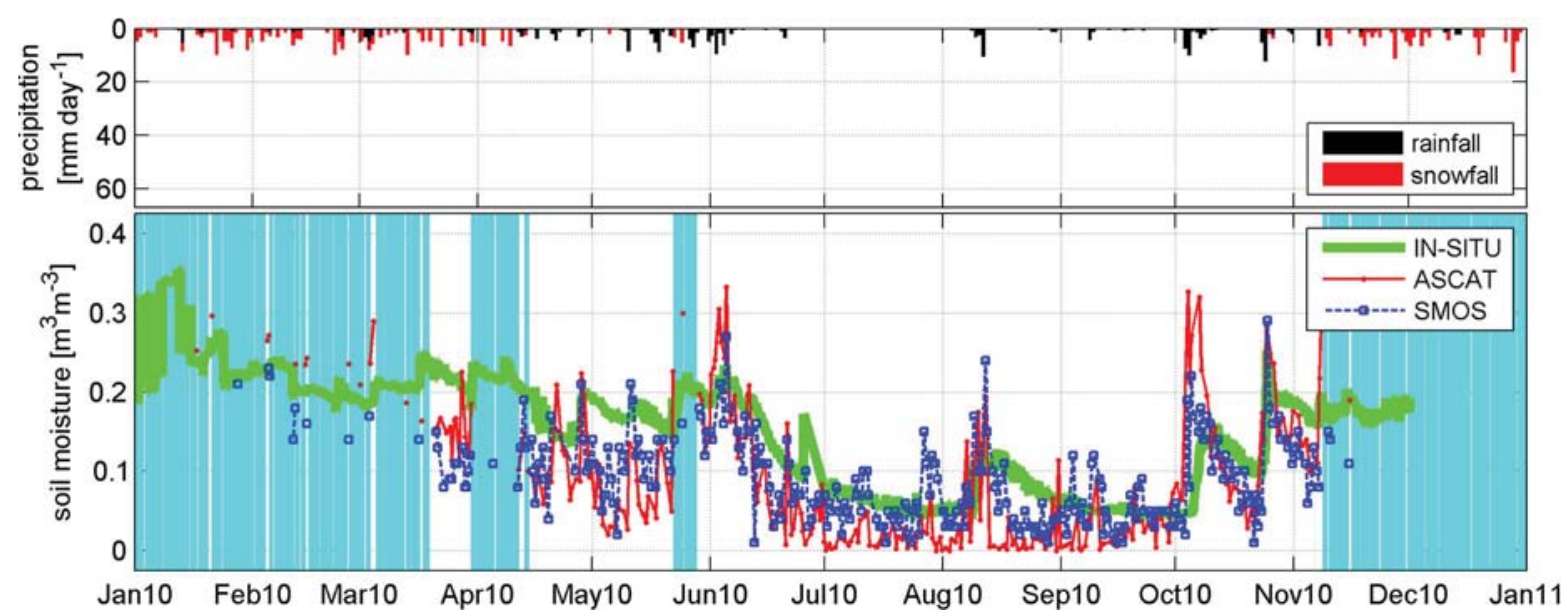

Fig. 4. Same as for Fig. 1 but for RC.

Next, we examine the seasonal behavior of the two satellite data sets. Overall, SMOS retrievals follow the seasonal evolution of the in situ data quite well. This is also the case for ASCAT retrievals at LW and RC. Over WG and LR, however, there are some problematic time periods when the ASCAT soil moisture values are consistently higher than what would be expected from the in situ and the SMOS data.

Over WG, ASCAT shows somewhat elevated soil moisture levels in the dry period from the beginning of May to midJuly (Fig. 1). Such behavior has been observed in other arid and semi-arid regions as well and is hypothesized to be due to volume scattering effects from dry subsurface soil layers [4]. Given that to date there is no solution to this problem, Wagner et al. [4] recommended that under completely dry conditions in arid environments, SMOS, AMSR-E, or other passive microwave soil moisture data (which are less affected by this phenomenon) should be used. Additional research is needed, however, to better identify the conditions under which the passive microwave data are preferable and to provide more reliable guidance to users.

Over LR, the problematic time period for ASCAT is from mid-June to the end of September (Fig. 3). One potential reason for the high ASCAT soil moisture data in summer may be that the parameterization of the vegetation correction term in the ASCAT retrieval is not optimal over this area (the seasonal behavior of the vegetation correction term looks reasonable but the magnitude may not be large enough). However, we do not exclude the possibility that the increased ASCAT signal during this period is also partly due to enhanced backscatter over wet soil surfaces and wetlands. As described by Jackson et al. [6], the LR region "is typified by broad floodplains with very poorly defined stream channels and gently sloping uplands." A visual inspection of optical images (e.g., on Google Maps) shows that there are hundreds of small lakes in this area. Furthermore, as can be seen in Fig. 3, according to GLDAS, rainfall occurred frequently during this period. Additional research that investigates, e.g., the backscatter behavior at a scale of $50-100 \mathrm{~m}$ using synthetic aperture radar data is needed to confirm or refute the aforementioned hypotheses. Note that SMOS also overestimates soil moisture slightly at LR during the same
TABLE I

ERror METRICS OF A COMPARISON OF SMOS AND ASCAT SOIL Moisture Data With In Situ Measurements Over Four USDA WATERSHEDS. FOR THE WG AND LR WATERSHEDS, THE ASCAT Results Are Also Shown After Masking the Problematic Summer Periods (See the Row Denoted by ASCAT $*$ ). $R$ Is the Correlation and $N$ Is the Number of Data Pairs. The SEE, the Bias, AND the RMSE ARe All Given IN $\mathrm{m}^{3} \mathrm{~m}^{-3}$. All Results ARe Statistically Significant With a P-Value Less Than 0.01

\begin{tabular}{|c|c|c|c|c|c|c|}
\hline & & $\mathrm{R}$ & SEE & BIAS & RMSE & $\mathrm{N}$ \\
\hline \multirow{3}{*}{} & SMOS & 0.74 & 0.041 & 0.018 & 0.045 & 339 \\
& ASCAT & 0.50 & 0.032 & -0.007 & 0.033 & 367 \\
& ASCAT* & 0.64 & 0.030 & -0.014 & 0.033 & 316 \\
\hline \multirow{2}{*}{} & SMOS & 0.80 & 0.045 & 0.019 & 0.048 & 307 \\
& ASCAT & 0.75 & 0.055 & 0.047 & 0.073 & 327 \\
\hline \multirow{2}{*}{} & SMOS & 0.55 & 0.052 & 0.058 & 0.078 & 346 \\
& ASCAT & 0.21 & 0.089 & 0.083 & 0.122 & 373 \\
& ASCAT* & 0.55 & 0.068 & 0.048 & 0.083 & 251 \\
\hline \multirow{2}{*}{} & SMOS & 0.65 & 0.048 & -0.030 & 0.057 & 270 \\
& ASCAT & 0.69 & 0.060 & -0.035 & 0.069 & 280 \\
\hline
\end{tabular}

period, which may similarly be related to the presence of water bodies or temporary standing water.

\section{B. Error Metrics}

The error metrics for SMOS and ASCAT from our analysis are summarized in Table I. For reference, this table also shows the ASCAT error metrics after masking the problematic time periods (May to mid-July for WG and mid-June to September for LR).

Overall, the correlations obtained by using morning and evening data for many more dates are somewhat smaller than those reported by Leroux et al. in their Table II, likely related to the differences in data versions and processing (Section II). With the exception of the ASCAT data over LR where the correlation is very low in our case $(R=0.21)$, we find that the correlations obtained for ASCAT are comparable with those obtained for SMOS and are within the expected statistical uncertainties for the sample sizes ([1, Fig. 6] provides error 
bars). These findings confirm the conclusion of Leroux et al. that "all products are equivalent in terms of correlation."

Finally, we now analyze the SEE, bias, and RMSE metrics that were not provided by Leroux et al. for ASCAT. The values for SMOS, as listed in Table I, agree reasonably well with those reported by Leroux et al. in their Table II, which suggests that these three metrics are somewhat less sensitive than the correlation to the selection and preprocessing of the data. Comparing the SEE, bias, and RMSE values for ASCAT with those for SMOS, Table I shows no clear advantage of SMOS over ASCAT to within the expected statistical uncertainties, again with the exception of the LR site when the problematic summer period is not masked. Over the WG site, the SEE, bias, and RMSE values for ASCAT are better than for SMOS, independent of whether the problematic time period for ASCAT from May to mid-July is masked or not.

Moreover, our Table I and Table II of Leroux et al. suggest that the differences in the RMSE values across the data sets are largely driven by differences in the bias, while the SEE values are roughly of the same order of magnitude. The statement in the abstract of Leroux et al. that SMOS "represents an [RMSE] improvement by a factor of 2-3 compared with the other products" must therefore be interpreted accordingly.

\section{CONCLUSION}

In this clarification on the study by Leroux et al. [1], we have demonstrated how the ASCAT data can be assessed quantitatively in the same manner as the SMOS data by using ancillary porosity data to convert the ASCAT degree of saturation index into volumetric soil moisture units. Our results show that ASCAT data are skillful and that there is no indication that the ASCAT soil moisture data are "very noisy" (as stated in the Abstract and Conclusions of Leroux et al.). While the ASCAT data clearly exhibit some unexpected behavior over the semiarid WG site during extremely dry conditions and over the humid LR site during the wet summer period, there is no evidence that ASCAT is "unstable" (as was stated in Leroux et al.) or two to three times more biased than the SMOS soil moisture data.

Furthermore, when the $R$ and SEE values are considered the skill values for all data sets (including the AMSR-E and ECMWF products considered only by Leroux et al.) are similar (to within the statistical uncertainties and within the framework of this comparison). The statement in Leroux et al. that SMOS "represents an improvement by a factor of 2-3 compared with the other products" is therefore valid only for the bias and only applies relative to AMSR-E and the ECWMF data in the now obsolete version investigated in [1].

More generally, the comparison of our results with those obtained by Leroux et al. illustrates how different choices in the selection, processing, and interpretation of the data may lead to different conclusions and rankings of soil moisture data sets. Despite the vast body of literature that deals with the validation of satellite soil moisture data, there is still a need for scientific studies that investigate different assumptions and choices made in the validation process (selection of study sites, screening and pre-processing of data sets, sample size, use of different error metrics, etc.). Additionally, future evaluation efforts for re- motely sensed soil moisture products could benefit from novel statistical approaches such as the triple collocation method [17], [18], the R-metric [19] or the use of alternative error metrics [12], [20]. However, we must recognize that the assessment of products also needs to consider the intended application and that different users may value a particular product and metric more than another. Thus, providing alternative metrics is a desirable goal.

\section{ACKNOWLEDGMENT}

The authors would like to thank European Space Agency for providing the SMOS Level 2 soil moisture data.

\section{REFERENCES}

[1] D. J. Leroux, Y. H. Kerr, A. A. Bitar, R. Bindlish, T. J. Jackson, B. Berthelot, and G. Portet, "Comparison between SMOS, VUA, ASCAT, and ECMWF soil moisture products over four watersheds in U.S.," IEEE Trans. Geosci. Remote Sens., vol. 52, no. 3, pp. 1562-1571, Mar. 2014.

[2] Y. H. Kerr, P. Waldteufel, P. Richaume, J. P. Wigneron, P. Ferrazzoli, A. Mahmoodi, A. Al Bitar, F. Cabot, C. Gruhier, S. E. Juglea, D. Leroux, A. Mialon, and S. Delwart, "The SMOS soil moisture retrieval algorithm," IEEE Trans. Geosci. Remote Sens., vol. 50, no. 5, pp. 1384-1403, May 2012.

[3] M. Owe, R. de jeu, and T. Holmes, "Multisensor historical climatology of satellite-derived global land surface moisture," J. Geophys. Res.-Earth Surf., vol. 113, no. 11, pp. F01002-1-F01002-17, Mar. 2008.

[4] W. Wagner, S. Hahn, R. Kidd, T. Melzer, Z. Bartalis, S. Hasenauer, J. Figa-Saldaña, P. de Rosnay, A. Jann, S. Schneider, J. Komma, G. Kubu, K. Brugger, C. Aubrecht, J. Züger, U. Gangkofner, S. Kienberger, L. Brocca, Y. Wang, G. Blöschl, J. Eitzinger, and K. Steinnocher, "The ASCAT soil moisture product: A review of its specifications, validation results, emerging applications," Meteorol. Zeitschrift, vol. 22, no. 1, pp. 5-33, Feb. 2013.

[5] C. Albergel, P. Rosnay, G. Balsamo, L. Isaksen, and J. M. Sabater, "Soil moisture analyses at ECMWF: Evaluation using global ground-based in situ observations," J. Hydrometeorol., vol. 13, no. 5, pp. 1442-1460, Oct. 2012.

[6] T. J. Jackson, M. H. Cosh, R. Bindlish, P. J. Starks, D. D. Bosch, M. Seyfried, D. C. Goodrich, M. S. Moran, and D. Jinyang, "Validation of advanced microwave scanning radiometer soil moisture products," IEEE Trans. Geosci. Remote Sens., vol. 48, no. 12, pp. 4256-4272, Dec. 2010.

[7] S. Bircher, N. Skou, and Y. H. Kerr, "Validation of SMOS L1C and L2 products and important parameters of the retrieval algorithm in the Skjern River catchment, Western Denmark," IEEE Trans. Geosci. Remote Sens., vol. 51, no. 5, pp. 2969-2985, May 2013.

[8] S. Hahn, T. Melzer, and W. Wagner, "Error assessment of the initial near real-time METOP ASCAT surface soil moisture product," IEEE Trans. Geosci. Remote Sens., vol. 50, no. 7, pp. 2556-2565, Jul. 2012.

[9] L. Brocca, F. Melone, T. Moramarco, W. Wagner, and S. Hasenauer, "ASCAT soil wetness index validation through in-situ and modeled soil moisture data in Central Italy," Remote Sens. Environ., vol. 114, no. 11, pp. 2745-2755, Nov. 2010.

[10] W. Wagner, Z. Bartalis, V. Naeimi, S.-E. Park, J. Figa-Saldana, and H. Bonekamp, "Status of the METOP ASCAT soil moisture product," in Proc. IEEE IGARSS, Honolulu, HI, USA, 2010, pp. 276-279.

[11] W. Wagner, G. Lemoine, and H. Rott, "A method for estimating soil moisture from ERS scatterometer and soil data," Remote Sens. Environ., vol. 70, no. 2, pp. 191-207, Nov. 1999.

[12] C.-H. Su, D. Ryu, R. I. Young, A. W. Western, and W. Wagner, "Intercomparison of microwave satellite soil moisture retrievals over Southeast Australia," Remote Sens. Environ., vol. 134, pp. 1-11, Jul. 2013.

[13] K. E. Saxton and W. J. Rawls, "Soil water characteristic estimates by texture and organic matter for hydrologic solutions," Soil Sci. Soc. Amer. J., vol. 70, no. 5, pp. 1569-1578, Sep./Oct. 2006.

[14] "Harmonized World Soil Database (Version 1.1)," IIASA, Laxenburg, Austria, 2009, FAO, Rome, Italy.

[15] M. Rodell, P. R. Houser, U. Jambor, J. Gottschalck, K. Mitchell, C. J. Meng, K. Arsenault, B. Cosgrove, J. Radakovich, M. Bosilovich, J. K. Entin, J. P. Walker, D. Lohmann, and D. Toll, "The global land 
data assimilation system," Bull. Amer. Meteorol. Soc., vol. 85, no. 3, pp. 381-394, Mar. 2004.

[16] C.-H. Su, D. Ryu, A. W. Western, and W. Wagner, "De-noising of passive and active microwave satellite soil moisture time series," Geophys. Res. Lett., vol. 40, no. 14, pp. 3624-3630, Jul. 2013.

[17] K. Scipal, T. Holmes, R. de Jeu, V. Naeimi, and W. Wagner, "A possible solution for the problem of estimating the error structure of global soil moisture data sets," Geophys. Res. Lett., vol. 35, no. 24, pp. L24403-1L24403-4, Dec. 2008.

[18] D. G. Miralles, W. T. Crow, and M. H. Cosh, "Estimating spatial sampling errors in coarse-scale soil moisture estimates derived from pointscale observations," J. Hydrometeorol., vol. 11, no. 6, pp. 1423-1429, Dec. 2010.
[19] W. T. Crow, D. G. Miralles, and M. H. Cosh, "A quasi-global evaluation system for satellite-based surface soil moisture retrievals," IEEE Trans. Geosci. Remote Sens., vol. 48, no. 6, pp. 2516-2527, Jun. 2010.

[20] D. Entekhabi, R. H. Reichle, R. D. Koster, and W. T. Crow, "Performance metrices for soil moisture retrievals and application requirements," J. Hydrometeorol., vol. 11, no. 3, pp. 832-840, Jun. 2010.

Authors' photographs and biographies not available at the time of publication. 